\title{
In Situ Generated Nickel Phosphide Based Catalysts for Hydroprocessing of Levulinic Acid
}

\author{
M. A. Golubeva ${ }^{a, *}$ \\ ${ }^{a}$ Topchiev Institute of Petrochemical Synthesis, Russian Academy of Sciences, Moscow, 119991 Russia \\ *e-mail: vinnikova@ips.ac.ru
}

Received November 14, 2020; revised December 16, 2020; accepted January 9, 2021

\begin{abstract}
This article describes the production of unsupported nickel phosphide catalysts generated in situ in a reaction mixture from water-soluble and oil-soluble precursors during the hydroconversion of levulinic acid. These catalysts contain crystalline phases, specifically $\mathrm{Ni}_{12} \mathrm{P}_{5}$ and $\mathrm{Ni}\left(\mathrm{PO}_{3}\right)_{2}$. During the hydrogenation of levulinic acid in toluene in the presence of NiP-TOP, a lower temperature and a shorter reaction time contribute to the formation of $\gamma$-valerolactone ( $100 \%$ selectivity). A higher temperature and a longer reaction time favor the formation of valeric acid ( $94 \%$ selectivity). In the hydrogenation of levulinic acid in ethanol in the presence of $\mathrm{NiP}-\mathrm{H}_{3} \mathrm{PO}_{2}$, the main reaction product is ethyl levulinate ( $95 \%$ selectivity).
\end{abstract}

Keywords: hydrodeoxygenation, hydrogenation, levulinic acid, $\gamma$-valerolactone, valeric acid, nickel phosphide

DOI: $10.1134 / \mathrm{S} 0965544121040022$

Biomass is one of the most promising renewable energy sources. The main components of lignocellulosic biomass are lignin, cellulose, and hemicellulose. Lignocellulosic biomass undergoes high-temperature acid-catalyzed hydrolysis to produce levulinic acid to be utilized in subsequent organic synthesis [1-3]. A large variety of levulinic acid products are formed in the course of hydrogenation and hydrodeoxygenation reactions.

The most common catalysts for the hydrogenation and hydrodeoxygenation of oxygen-containing substrates are noble metals, non-noble transition metals, and transition metal sulfides deposited on an acidic or neutral support [4-6]. Carbides, phosphides, and nitrides of transition metals are also used for this purpose, though less commonly [5-7].

Transition metal phosphides, both supported and unsupported, are used in hydroprocessing. Unsupported metal phosphides have been studied in application to the hydroprocessing of phenols [8-12], as well as higher fatty acids and their esters [13-15].

References [16-18] suggest a method for the hydrodeoxygenation of oxygen-containing compounds in the presence of transition metal phosphides, which involves in situ generation of an unsupported phosphide active phase directly in the hydrodeoxygenation reactor.
This method has been well known to be employed for hydroconversion of heavy oil residues in the presence of transition metal sulfides, which can be generated in situ from oxides due to $\mathrm{H}_{2} \mathrm{~S}$ formation in the reaction mixture [19].

The purpose of this study was to prepare in situ nickel phosphides in the reaction mixture and to examine their catalytic activity in the hydroprocessing of levulinic acid.

\section{EXPERIMENTAL}

Nickel(II) acetate tetrahydrate (Sigma-Alrdrich, 98\%) and hypophosphorous acid (Sigma-Aldrich, $50 \mathrm{wt} \%$ in $\mathrm{H}_{2} \mathrm{O}$ ) were used as precursors to prepare a $\mathrm{NiP}-\mathrm{H}_{3} \mathrm{PO}_{2}$ catalyst. Nickel(II) 2-ethylhexanoate (Aldrich, 78 wt \% in 2-ethylhexanoic acid) and trioctylphosphine (Acros Organics, 90\%) were taken as precursors to prepare a NiP-TOP catalyst. Levulinic acid (Sigma-Alrdrich, $>97 \%$ ) was used as a hydrogenation substrate, while toluene (Komponent-Reaktiv, $>99 \%$ ) and ethanol (Reachem, >99\%) were used as solvents. Acetone (Komponent-Reaktiv, technical grade), petroleum ether 70/100 (Komponent-Reaktiv, technical grade), gaseous $\mathrm{H}_{2}$ (Air Liquide, $\geq 98 \%$ ), and $\mathrm{Ar}$ (Air Liquide, $\geq 98 \%$ ) were also used in the study. The ethanol was held over $3 \AA$ molecular sieves (Sigma-Aldrich, $3.2 \mathrm{~mm}$ pellets) to 
(a)

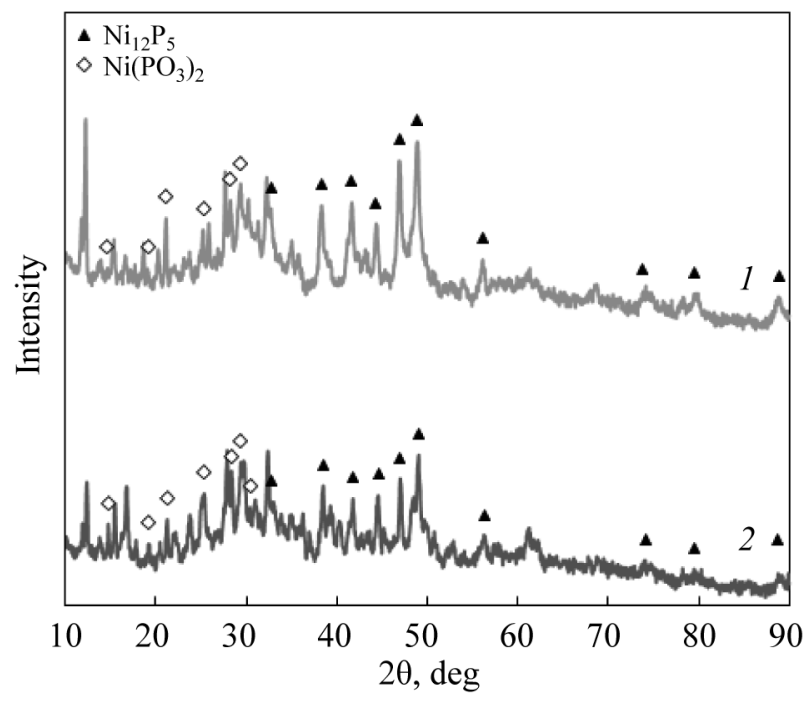

(b)

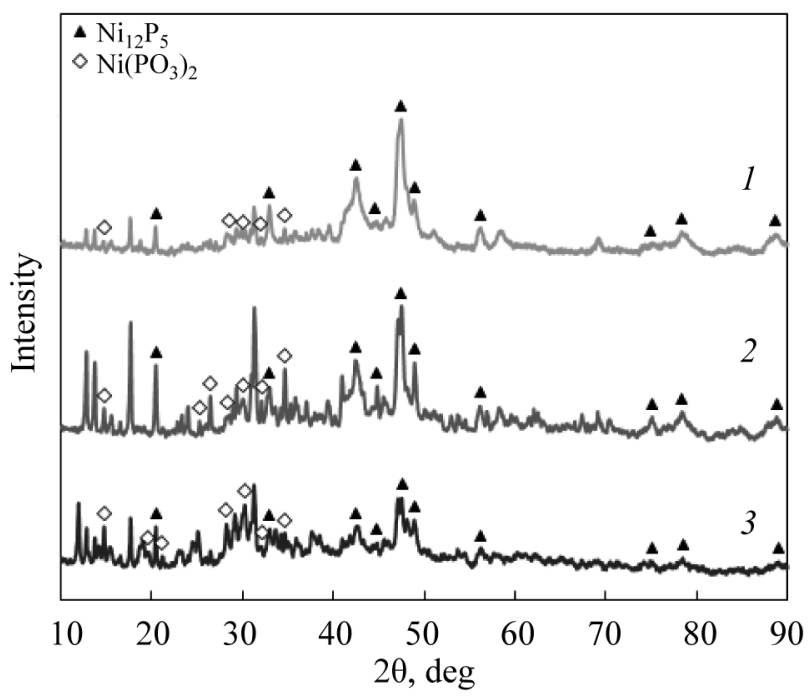

Fig. 1. XRD patterns of catalyst samples: (a) NiP-TOP prepared in situ from oil-soluble precursors in toluene at: (1) 300 and (2) $350^{\circ} \mathrm{C}$; (b) $\mathrm{NiP}-\mathrm{H}_{3} \mathrm{PO}_{2}$ prepared in situ from water-soluble precursors in ethanol at: (1) 250, (2) 300, and (3) $350^{\circ} \mathrm{C}$.

remove water. The remaining reagents were used without pretreatment.

Nickel phosphide based catalysts were prepared in situ from water-soluble and oil-soluble precursors in a stainless steel slurry reactor during a series of catalytic tests. A mixture of nickel(II) acetate [or nickel(II) 2-ethylhexanoate] and hypophosphorous acid (or trioctylphosphine) $(\mathrm{P} / \mathrm{Ni}$ molar ratio $=2)$, as well as $5 \mathrm{wt} \%$ of levulinic acid solution (substrate/Ni molar ratio = 25 ) in ethanol (or toluene), were introduced into the reactor. The $\mathrm{H}_{2}$ initial pressure was $5 \mathrm{MPa}$. The reactor was heated to $250-350^{\circ} \mathrm{C}$ under vigorous stirring for $1-6 \mathrm{~h}$. The liquid products were centrifuged (5000 rpm) from the catalyst. The resultant catalysts were labeled $\mathrm{NiP}-\mathrm{H}_{3} \mathrm{PO}_{2}$ and NiP-TOP, respectively. To remove the residues of water-soluble and oil-soluble precursors, the $\mathrm{NiP}-\mathrm{H}_{3} \mathrm{PO}_{2}$ was washed successively with water and acetone, while the NiP-TOP was washed with petroleum ether. The catalysts were dried and stored in an inert argon atmosphere.

The liquid products were qualitatively analyzed using a ThermoFischer Scientific Thermo Focus DSQ II gas-liquid chromatograph (GLC) equipped with a mass-spectrometric detector, a Varian VF-5MS capillary column $(30 \mathrm{~m} \times 0.25 \mathrm{~mm} \times 0.25 \mu \mathrm{m})$, and helium as a carrier gas. NIST/EPA/NIH databases were used to identify components. The liquid products were quantitatively analyzed on a Crystal-Lux 4000M GLC (produced by "Meta-Chrom" Research and Production Company) equipped with a flame ionization detector, a Supelco Incorporated SPB-1 capillary column $(30 \mathrm{~m} \times 0.25 \mathrm{~mm} \times 0.25 \mu \mathrm{m})$, and helium as a carrier gas. The NetChromWin software package was used for the chromatographic analysis and interpretation of the chromatograms.

X-ray diffraction (XRD) of the catalyst samples was performed using a Rotaflex RU-200 diffractometer (in $\mathrm{Cu} K_{\alpha}$ radiation) equipped with a Rigaku Corporation $\mathrm{D} / \mathrm{Max}-\mathrm{RC}$ goniometer (rotation rate $1^{\circ} 2 \theta / \mathrm{min}$, step $0.04^{\circ}, 2 \theta$ range $10^{\circ}-90^{\circ}$ ). The qualitative phase analysis of the samples was performed using the ICDD PDF-2 database and the MDI Jade ${ }^{\circledR}$ software package.

\section{RESULTS AND DISCUSSION}

The in situ generated nickel phosphide catalysts were examined by XRD. The examination confirmed the generation of a crystalline nickel phosphide phase in the $\mathrm{NiP}-\mathrm{TOP}$ samples prepared at $300-350^{\circ} \mathrm{C}$ in toluene after $6 \mathrm{~h}$ of the reaction (Fig. 1a) and in the $\mathrm{NiP}-\mathrm{H}_{3} \mathrm{PO}_{2}$ samples prepared at $250-350^{\circ} \mathrm{C}$ in ethanol after $6 \mathrm{~h}$ of the reaction (Fig. 1b). The NiP-TOP obtained at $250^{\circ} \mathrm{C}$ was not separated from the reaction mixture by centrifugation. A nickel phosphide phase $\left(\mathrm{Ni}_{12} \mathrm{P}_{5}\right)$ and a nickel metaphosphate phase $\left[\mathrm{Ni}\left(\mathrm{PO}_{3}\right)_{2}\right]$ were identified 
(a)

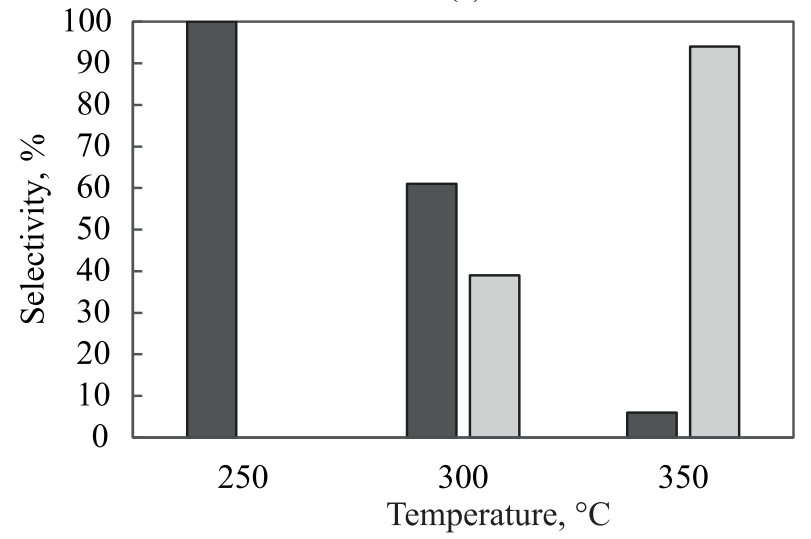

(b)

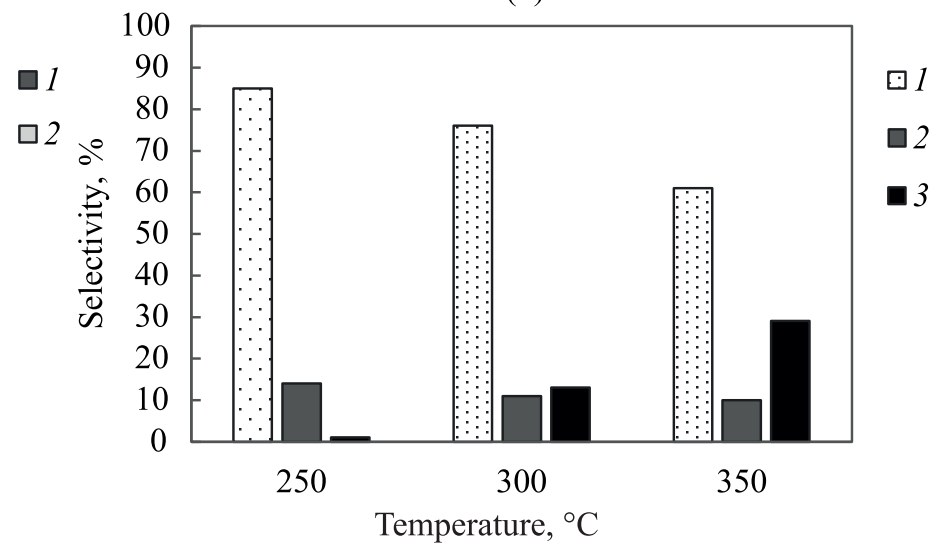

Fig. 2. Effects of reaction temperature on distribution of levulinic acid hydrogenation products: (a) in toluene, over NiP-TOP [(1) $\gamma$-valerolactone, (2) valeric acid]; and (b) in ethanol, over $\mathrm{NiP}-\mathrm{H}_{3} \mathrm{PO}_{2}[(1)$ ethyl levulinate, (2) $\gamma$-valerolactone, (3) ethyl valerate].

(PDF\#22-1190 and PDF\#28-0708, respectively) in all the catalyst samples. Some of the reflections were not identified.

The catalytic activity of the NiP-TOP and NiP- $\mathrm{H}_{3} \mathrm{PO}_{2}$ nickel phosphides generated in situ was examined in the hydrogenation of levulinic acid. All conversions of levulinic acid occurred both on metal active sites (Ni in $\mathrm{Ni}_{12} \mathrm{P}_{5}$ ) and on acid active sites [16]. The phosphate group in $\mathrm{Ni}\left(\mathrm{PO}_{3}\right)_{2}$ shows Brønsted acid site properties, whereas $\mathrm{Ni}^{2+}$ in $\mathrm{Ni}\left(\mathrm{PO}_{3}\right)_{2}$ exhibits the properties of a Lewis acid site.

The temperature effects on the reaction product yields were examined for $6 \mathrm{~h}$. The levulinic acid conversion in toluene in the presence of nickel phosphide generated in situ (NiP-TOP) reached 100\%. $\gamma$-Valerolactone and valeric acid were identified as levulinic acid hydrogenation products (Fig. 2a). At $250^{\circ} \mathrm{C}, \gamma$-valerolactone was produced with $100 \%$ selectivity. There are two alternative routes of levulinic acid conversion into this compound: the dehydration of levulinic acid into angelica lactone followed by its reduction to $\gamma$-valerolactone; or the reduction of levulinic acid to 4-hydroxyvaleric acid followed by dehydrocyclization into $\gamma$-valerolactone (Scheme 1) $[20,21]$. As the temperature was elevated to $300^{\circ} \mathrm{C}$, the $\gamma$-valerolactone selectivity declined to $61 \%$, whereas valeric acid was identified as an additional reaction product (with 39\% selectivity). Valeric acid is formed by two routes: dehydration followed by hydrogenation of 4-hydroxyvaleric acid $[22,23]$; or decyclization of $\gamma$-valerolactone followed by hydrogenation (Scheme 1) [24]. A further temperature elevation to $350^{\circ} \mathrm{C}$ resulted in a $\gamma$-valerolactone selectivity drop to $6 \%$ and a valeric acid selectivity boost to $94 \%$. Thus, a lower temperature $\left(250^{\circ} \mathrm{C}\right)$ promotes the formation of $\gamma$-valerolactone, while a higher temperature $\left(350^{\circ} \mathrm{C}\right)$ favors the formation of valeric acid.

The levulinic acid conversion in ethanol in the presence of nickel phosphide generated in situ $\left(\mathrm{NiP}-\mathrm{H}_{3} \mathrm{PO}_{2}\right)$ reached $100 \%$. Ethyl levulinate, $\gamma$-valerolactone, and ethyl valerate were identified as levulinic acid hydrogenation products (Fig. 2b). Among them, ethyl levulinate was the main reaction product (Scheme 1). With temperature elevation, the ethyl levulinate and $\gamma$-valerolactone selectivities declined, while the ethyl valerate selectivity increased. The highest selectivity values achieved were: $85 \%$ for ethyl levulinate (at $250^{\circ} \mathrm{C}$ ), $14 \%$ for $\gamma$-valerolactone (at $250^{\circ} \mathrm{C}$ ), and $29 \%$ for ethyl valerate (at $350^{\circ} \mathrm{C}$ ).

The effects of reaction time on the product yields were examined at $350^{\circ} \mathrm{C}$. The levulinic acid conversion in toluene in the presence of nickel phosphide generated in situ (NiP-TOP) reached $100 \%$. $\gamma$-Valerolactone and valeric acid were identified as levulinic acid hydrogenation products (Fig. 3a). As the reaction time was extended, the $\gamma$-valerolactone selectivity declined, whereas the valeric acid selectivity increased. The highest selectivity values achieved were: $80 \%$ for $\gamma$-valerolactone (after $1 \mathrm{~h}$ of the reaction), and 94\% for valeric acid (after $6 \mathrm{~h}$ ). Thus, a shorter reaction time promotes the formation of $\gamma$-valerolactone, while a longer reaction time favors the formation of valeric acid. The achievement of full levulinic acid conversion after $1 \mathrm{~h}$ of the reaction suggests that valeric acid is produced through the formation of $\gamma$-valerolactone and pentenoic acid (Scheme 1). 
Scheme 1. Routes of levulinic acid conversion in presence of nickel phosphide catalysts.

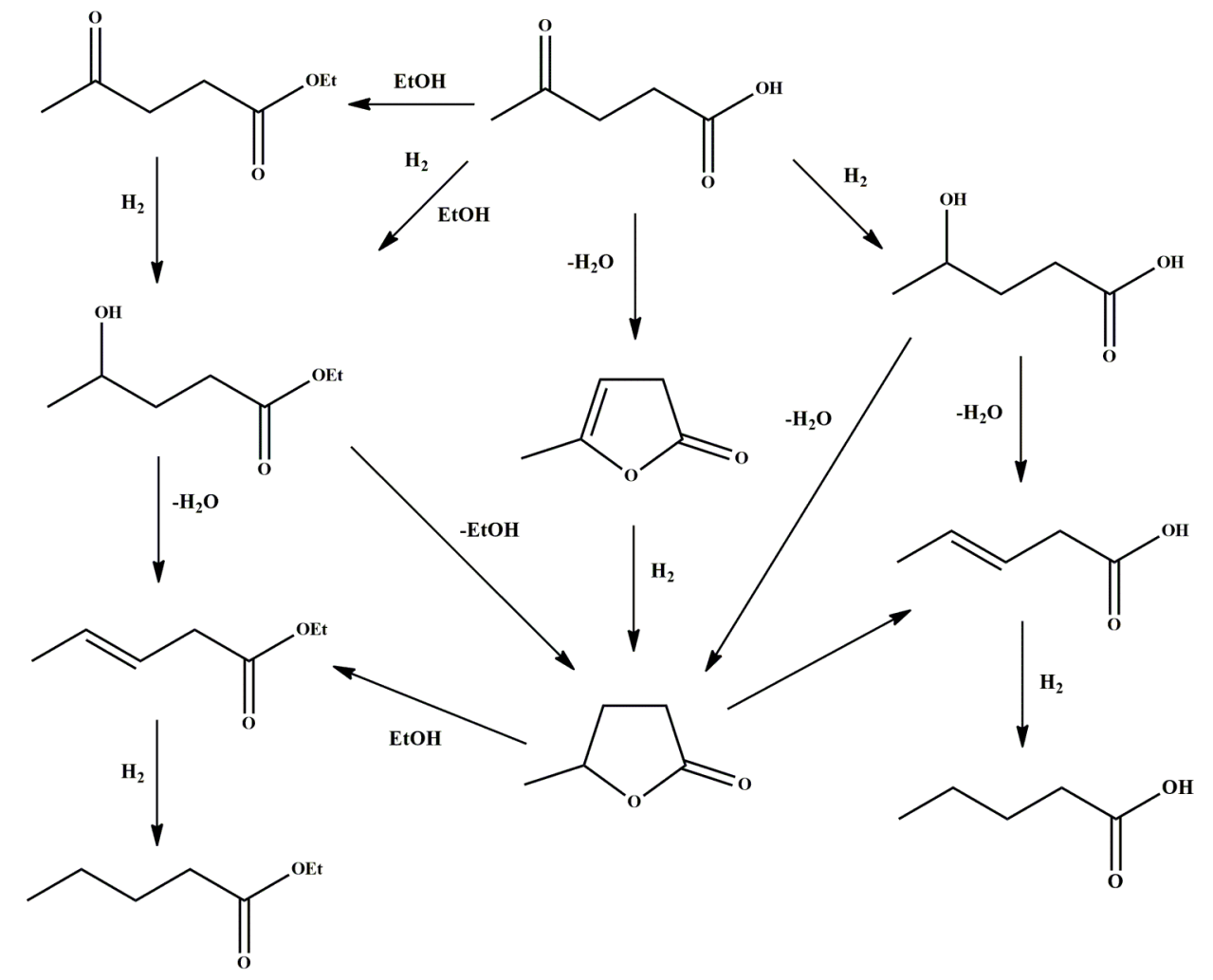

The levulinic acid conversion in ethanol in the presence of nickel phosphide generated in situ $\left(\mathrm{NiP}-\mathrm{H}_{3} \mathrm{PO}_{2}\right)$ reached $100 \%$. Ethyl levulinate, $\gamma$-valerolactone, and ethyl valerate were identified as levulinic acid hydrogenation products (Fig. 3b). The highest selectivity values achieved were: $95 \%$ for ethyl levulinate (after $1 \mathrm{~h}$ of the reaction), 10\% for

(a)

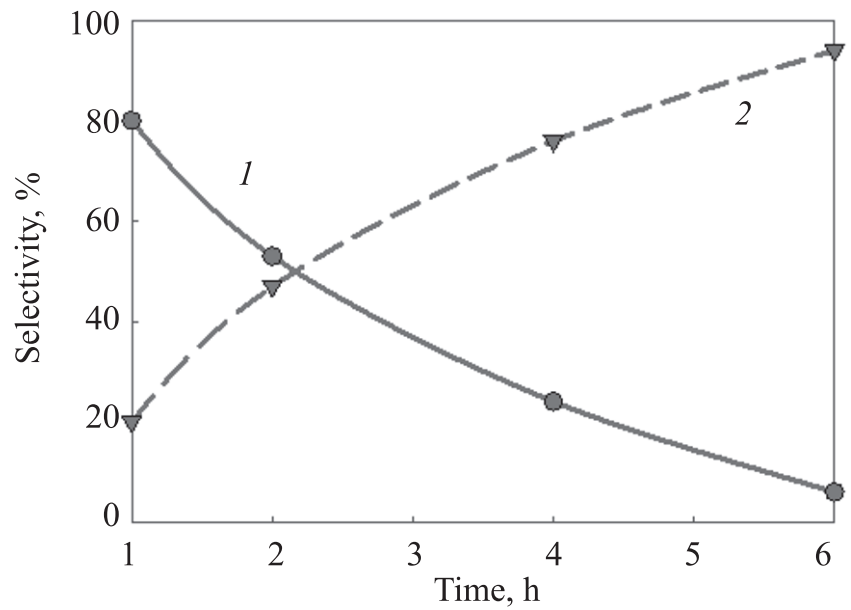

$\gamma$-valerolactone (after $6 \mathrm{~h}$ ), and 29\% for valeric acid (after $6 \mathrm{~h}$ ).

\section{CONCLUSIONS}

The use of oil-soluble and water-soluble nickel and phosphorus precursors makes it possible to prepare in situ catalyst samples that contain a nickel phosphide phase

(b)

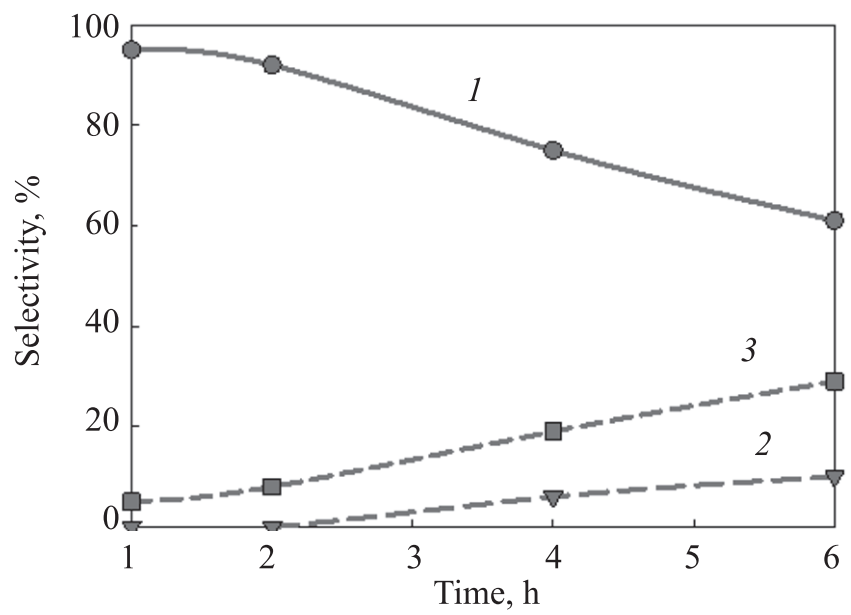

Fig. 3. Effects of reaction time on distribution of levulinic acid hydrogenation products: (a) in toluene, over NiP-TOP $[(1) \gamma$-valerolactone, (2) valeric acid]; and (b) in ethanol, over $\mathrm{NiP}-\mathrm{H}_{3} \mathrm{PO}_{2}$ [(1) ethyl levulinate, (2) $\gamma$-valerolactone, (3) ethyl valerate]. 
$\left(\mathrm{Ni}_{12} \mathrm{P}_{5}\right)$ and a nickel metaphosphate phase $\left[\mathrm{Ni}\left(\mathrm{PO}_{3}\right)_{2}\right]$. The resultant catalysts are active in the hydrogenation and hydrodeoxygenation of levulinic acid. The phosphate phase promotes the acid-catalyzed reactions [16]. Levulinic acid hydrogenation in toluene in the presence of NiP-TOP generates $\gamma$-valerolactone and valeric acid. A lower temperature and a shorter process time contribute to the formation of $\gamma$-valerolactone, while a higher temperature and a longer reaction time favor the formation of valeric acid. Levulinic acid hydrogenation in ethanol in the presence of $\mathrm{NiP}-\mathrm{H}_{3} \mathrm{PO}_{2}$ generates ethyl levulinate, $\gamma$-valerolactone, and ethyl valerate, where ethyl levulinate is the main product. Thus, $\gamma$-valerolactone, valeric acid, and ethyl levulinate can be produced with high selectivity by varying the reaction conditions, the phosphide precursors, and the solvent.

\section{AUTHOR INFORMATION}

M.A. Golubeva, ORCID: http://orcid.org/0000-0002-37417833

\section{ACKNOWLEDGMENTS}

This work was performed using equipment of Center for Collective Use "TIPS RAS Analytical center of deep oil processing and petrochemistry."

\section{FUNDING}

This work was carried out within the State Program of TIPS RAS.

\section{CONFLICT OF INTEREST}

The author declares no conflict of interest requiring disclosure in this article.

\section{OPEN ACCESS}

This article is licensed under a Creative Commons Attribution 4.0 International License, which permits use, sharing, adaptation, distribution and reproduction in any medium or format, as long as you give appropriate credit to the original author(s) and the source, provide a link to the Creative Commons license, and indicate if changes were made. The images or other third party material in this article are included in the article's Creative Commons license, unless indicated otherwise in a credit line to the material. If material is not included in the article's Creative Commons license and your intended use is not permitted by statutory regulation or exceeds the permitted use, you will need to obtain permission directly from the copyright holder. To view a copy of this license, visit http://creativecommons.org/licenses/by/4.0/.

\section{REFERENCES}

1. Fitzpatrick, S.W., Feedstocks for the Future, Washington, DC: American Chemical Society, 2006, pp. 271-287. https://doi.org/10.1021/bk-2006-0921.ch020

2. Rackemann, D.W. and Doherty, W.O.S., Biofuel. Bioprod. Biorefin., 2011, vol. 5, pp. 198-214. https://doi.org/10.1002/bbb.267

3. Leonard, R.H., Ind. Eng. Chem., 1956, vol. 48, pp. 1330 1341. https://doi.org/10.1021/ie50560a033

4. De, S., Saha, B., and Luque, R., Bioresour. Technol., 2015, vol. 178, pp. 108-118. https://doi.org/10.1016/j.biortech.2014.09.065

5. Saidi, M., Samimi, F., Karimipourfard, D., Nimmanwudipong, T., Gates, B.C., and Rahimpour, M.R., Energy Environ. Sci., 2014, vol. 7, pp. 103-129. https://doi.org/10.1039/c3ee43081b

6. Jin, W., Pastor-Pérez, L., Shen, D., SepúlvedaEscribano, A., Gu, S., and Ramirez Reina, T., ChemCatChem., 2019, vol. 11, pp. 924-960. https://doi.org/10.1002/cctc.201801722

7. Oyama, S.T., Gott, T., Zhao, H., and Lee, Y.-K., Catal. Today, 2009, vol. 143, pp. 94-107. https://doi.org/10.1016/j.cattod.2008.09.019

8. Yu,Z., Wang, Y., Sun, Z., Li, X., Wang,A., Camaioni, D.M., and Lercher, J.A., Green Chem., 2018, vol. 20, pp. 609-619. https://doi.org/10.1039/c7gc03262e

9. Wang, W., Zhang, K., Liu, H., Qiao, Z., Yang, Y., and Ren, K., Catal. Commun., 2013, vol. 41, pp. 41-46. https://doi.org/10.1016/j.catcom.2013.07.003

10. Yu, Z., Yao, K., Wang, Y., Yao, Y., Sun, Z., Liu, Y., Shi, C., Wang, W., and Wang, A., Catal. Today, 2020. In press. https://doi.org/10.1016/j.cattod.2020.06.006

11. Whiffen, V.M.L. and Smith, K.J., Energy Fuels, 2010, vol. 24, pp. 4728-4737. https://doi.org/10.1021/ef901270h

12. Inocêncio, C.V.M, De Souza, P.M., Rabelo-Neto, R.C., Teixeira da Silva, V., and Bellot Noronha, F., Catal. Today, 2020. In press.

https://doi.org/10.1016/j.cattod.2020.07.077

13. Peroni, M., Lee, I., Huang, X., Baráth, E., Oliver, Y., Gutiérrez, O.Y., and Lercher, J.A., ACS Catal., 2017, vol. 7, pp. 6331-6341. https://doi.org/10.1021/acscatal.7b01294

14. Yang, Y., Ochoa-Hernández, C., Pizarro, P., de la Peña O'Shea, V.A., Coronado, J.M., and Serrano, D.P., Top. 
Catal., 2012, vol. 55, pp. 991-998.

https://doi.org/10.1007/s11244-012-9886-z

15. Peroni, M., Mancino, G., Baráth, E., Gutiérrez, O.Y., and Lercher, J.A., Appl. Catal. B, 2016, vol. 180, pp. 301-311.

https://doi.org/10.1016/j.apcatb.2015.06.042

16. Golubeva, M.A. and Maximov, A.L., Appl. Catal. A, 2020, vol. 6. ID 117890.

https://doi.org/10.1016/j.apcata.2020.117890

17. Golubeva, M.A. and Maximov, A.L., Mendeleev Commun., 2019, vol. 29, pp. 550-552.

https://doi.org/10.1016/j.mencom.2019.09.024

18. Golubeva, M.A. and Maximov, A.L., Petrol. Chem., 2019, vol. 59, pp. 1326-1330.

https://doi.org/10.1134/S0965544119120041

19. Khadzhiev, S.N., Kadiev, Kh.M., and Kadieva, Kh.M., Petrol. Chem., 2014, vol. 54, pp. 323-346.

https://doi.org/10.1134/S0965544114050065
20. Upare, P.P., Lee, J.-M., Hwang, D.W., Halligudi, S.B., Hwang, Y.K., and Chang, J.-S., J. Ind. Eng. Chem., 2011, vol. 17, pp. 287-292.

https://doi.org/10.1016/j.jiec.2011.02.025

21. Xu, Q., Li, X., Pan, T., Yu, C., Deng, J., Guo, Q., and Fu, Y., Green Chem., 2016, vol. 18, pp. 1287-1294. https://doi.org/10.1039/c5gc01454a

22. Mohan, V., Venkateshwarlu, V., Pramod, C.V., Raju, B.D., and Rao, K.S.R., Catal. Sci. Technol., 2014, vol. 4, pp. 1253-1259.

https://doi.org/10.1039/c3cy01072d

23. Pan, T., Deng, J., Xu, Q., Xu, Y., Guo, Q.-X., and Fu, Y., Green Chem., 2013, vol. 15, pp. 2967-2974. https://doi.org/10.1039/c3gc40927a

24. Karanwal, N., Verma, D., Butolia, P., Kim, S.M., and Kim, J., Green Chem., 2020, vol. 22, pp. 766-787.

https://doi.org/10.1039/c9gc03516h 